DOI: $10.26851 /$ RUCP.27.3

\title{
ENTRE LA REPÚBLICA Y LA DEMOCRACIA: JUSTINO JIMÉNEZ DE ARÉCHAGA*
}

\author{
Between the Republic and Democracy: Justino Jiménez de Aréchaga
}

Javier Gallardo ${ }^{1}$

Resumen: Este trabajo reconstruye la génesis normativa de la democracia uruguaya en base al pensamiento de Justino Jiménez de Aréchaga, figura de relieve de las lides doctrinarias y políticas del Uruguay decimonónico. El texto cataloga el pensamiento de Aréchaga como un momento relevante en el camino de afirmación normativa e institucional de la política uruguaya. Por un lado, se pone énfasis en su amalgama teórica de postulados liberales, republicanos y democráticos, destacándose sus fórmulas combinatorias de un perfeccionismo cívico con un realismo democrático. Por otro, se analiza, junto a algunos claroscuros del discurso teórico de Aréchaga, su contribución a los fundamentos de una política pluralista y su anticipación a algunos arreglos institucionales fundamentales de la democracia de partidos en Uruguay, mayormente consagrados en la Constitución de 1917. Finalmente, se pasa revista al legado normativo del autor, resumiendo las distancias y cercanías de su pensamiento respecto a algunos problemas teóricos de actualidad y a ciertos rasgos centrales de la democracia uruguaya.

Palabras clave: Teoría Política, Republicanismo, Democracia, Constitución.

Summary: This paper reconstructs the normative genesis of Uruguayan democracy based on the thought of Justino Jiménez de Aréchaga, a prominent figure of the doctrinal and political ideals of the 19th century in the country. The text catalogs Aréchaga's thought as a relevant moment in the path of normative and institutional affirmation of Uruguayan politics. On the one hand, the article foucuses on his theoretical amalgam of liberal, republican and democratic postulates, emphasizing his combinatorial formulas of a civic perfectionism with a democratic realism. On the other hand, along with some chiaroscuro of Aréchaga's theoretical discourse, the text analyzes his contribution to the foundations of pluralistic politcs and his anticipation to some fundamental institutional arrangements of party democracy in Uruguay, mostly enshrined in the 1917 Constitution. Finally, the author's normative legacy is reviewed, summarizing the distances and closeness of his thinking with respect to some current theoretical problems and certain central features of Uruguayan democracy.

Key words: Political Theory, Republicanism, Democracy, Constitution.

\footnotetext{
* Artículo recibido el 30/11/2017 y aceptado el 22/03/2018.

1 Instituto de Ciencia Política, Facultad de Ciencias Sociales, Universidad de la República. Correo electrónico: javiergallardoicp@gmail.com
} 


\section{Introducción}

La democracia es objeto de distintos tratamientos teóricos, los cuales se inscriben, de una manera o de otra, en diversas tradiciones de conocimiento y pensamiento político. Mientras los enfoques de impronta cognitiva, inspirados en epistemologías objetivantes o en heurísticas hermenéuticas, privilegian el conocimiento de los hechos y comportamientos políticos, cuando no los significados y sentidos interpretativos de la vida política, administrando una separación -de inspiración filosófica o metodológica- entre realidades positivas o prácticas simbólicas y principios o valoraciones prescriptivos, la tradición normativa ha tenido a su cargo la clarificación de los fundamentos justificativos y valorativos de las instituciones y decisiones de la política en general, y de la democracia, en particular.

Contrariamente a los conocimientos centrados en realidades empíricas o en mediaciones simbólicas, la tradición normativa privilegia las condiciones fundantes de los poderes políticos, los juicios valorativos -objetivos o intersubjetivos- de las cosas políticas y sus fundamentos de validez. Apelando a modelamientos trascendentes o constructivos de los ordenamientos políticos históricos, ya sea en base al imperativo de un deber ser fundado en principios o valores independientes de las realidades históricamente dadas o establecidas, ya sea conforme a un ideal de autocontrol racional y sustantivo de la contingencia político-social, dicha tradición ha venido transitando, desde larga data, por el terreno de los principios fundacionales y las prescripciones prácticas o institucionales ${ }^{2}$.

En una aproximación indirecta a esta disciplina teórica, particularmente cultivada por la filosofía política tradicional, este texto incursiona en los trabajos de un ejemplar representante del linaje normativo de la política uruguaya, Justino Jiménez de Aréchaga, primero de una dinastía familiar de conocidos tratadistas constitucionales uruguayos, cuyas ideas y conceptos, aún escasamente estudiados por la ciencia política local, contribuyeron a trazar, más allá de su contexto de enunciación y de su textualidad discursiva, el camino hacia una democracia de partidos en el Uruguay, anticipando algunos de sus arreglos institucionales fundamentales, mayormente consagrados en la Constitución de 1917.

De moderna progenie ilustrada, universalista y racionalista, Aréchaga es un fiel exponente de la tradición del moralismo político y del razonamiento práctico. Con todo, la normatividad prescriptiva de Aréchaga, conjugada en el lenguaje tradicional del derecho público y constitucional, no responde a una ficción constitutiva o totalizante de un orden político ideal, sino que tiende a ajustarse, más bien, al talle de los principios y de los juicios intersubjetivos, los cuales son elevados a la categoría de un fundamento racional de las condiciones de validez de un régimen demo-constitucional, sin dejar de transitar por algunos problemas trascendentes de la democracia y singularmente acuciantes en los tiempos embrionarios de la democracia uruguaya.

2 Para un examen de las diferencias entre los tratamientos normativo-universalistas e históricointerpretativos de la política véase Taylor (1990) Shapiro (1990) y Plant (1991). Para una discusión de los enfoques empíricos y evaluativos de la ciencia política véase Weber (1980), Sartori (1984) Dahl (1991) y Weale (1999). 
Pese a no escatimar acopios de datos y a reivindicar el valor cognitivo de las evidencias empíricas, el itinerario teórico de Aréchaga responde a una axiomática normativa inscripta en una perspectiva de moralidad política que tanto remite a la tradición de la filosofía práctica como a una "ciencia del legislador", sensibles a la integridad moral de la vida política y a las normas constitutivas de un orden institucional, sin dejar de incursionar en un tratamiento analítico y positivo, teórico e histórico, del derecho electoral, pieza fundamental de los arreglos políticos fundacionales de la democracia de partidos en el Uruguay (Lanzaro, 2012; Buquet y Castellano, 1995; Caetano, Rilla y Pérez, 1988; Pérez, 1988). En definitiva, además de rendir culto a las "verdades teóricas", antepuestas a "las posibilidades y conveniencias de las aplicaciones prácticas", Aréchaga cultivó una disciplina teórica caracterizada por su tendencia articular los ordenamientos prescriptivos con la integridad fáctica y decisoria de las cosas políticas ${ }^{3}$.

En este trabajo se aborda la aproximación de Aréchaga a la cuestión de la validez y deseabilidad de un régimen demo-republicano y sus empeños por justificar, desde categóricos mandatos normativos, no exentos de cierta racionalidad prudencial, su plena adopción en el Uruguay de su tiempo. A su vez, se pone especial énfasis en su empresa de fundamentación ética de una ciudadanía activa y en su pertenencia a una tradición republicana de fuertes arraigos en el pensamiento político nacional, sin dejar de considerar su participación en la elaboración de un guión pluralista de la democracia de partidos en el Uruguay.

Desde luego, quien se aproxime hoy a los escritos de esta figura señera de la intelectualidad política nacional encontrará algunos problemas propios de sus fuentes de inspiración normativa, debiendo confrontarse con los sedimentos arqueológicos de una escuela teórica inevitablemente marcada, para bien o para mal, por una época histórica. Incluso, una genuina comprensión y un juicio pertinente de la escritura de Aréchaga deberá abrirse camino entre los dogmas metafísicos y especulativos de una élite erudita y doctrinaria, enfrentada a los avances de una era democrática, al decir de Tocqueville, particularmente pujante en el Nuevo Mundo, de ímpetus niveladores o masificadores, abonada por el sufragio universal y necesariamente encaminada hacia la política de partidos.

Con todo, pese a sus restricciones históricas, a sus especificidades semánticas y al carácter controvertible de algunos de sus alineamientos conceptuales y valorativos, los trabajos de Aréchaga, plasmados en tiempos autoritarios de la política nacional, sintonizan con algunas líneas maestras de la Teoría Política moderna y contemporánea, dando cuenta de algunos problemas consustanciales al pensamiento y la práctica de la política democrática. De modo que una revisita a este autor no debería resultar

3 Activo impulsor del racionalismo liberal y anticlerical del siglo XIX, catedrático de Derecho Constitucional entre 1873 y 1884, miembro fundador del Partido Constitucional en 1880 y legislador del Partido Nacional, Justino Jiménez de Aréchaga (1850-1904) disfrutó de amplios prestigios académicos y políticos, dentro y fuera de fronteras, particularmente por su erudición en cuestiones electorales. Con todo, la relevancia intelectual de Aréchaga se advierte en su magisterio en las aulas de derecho constitucional y en el ascendiente que ejerciera en la formación de diversas generaciones de especialistas en derecho público, tal como lo sostiene un saber académico convencional y lo revelan también las tesis de doctorado en derecho de las últimas décadas del siglo XIX, fuertemente inspiradas en su doctrina constitucional. 
ociosa para quien se interese por los modos convencionales de justificar la democracia y por algunas herencias teóricas de la democracia uruguaya, fraguadas en encrucijadas históricas relevantes y vigentes, de algún modo, hasta hoy.

\section{La fundación teórica de una democracia liberal-republicana}

Los escritos políticos de Aréchaga contienen una amalgama de elementos teóricos liberales, republicanos y democráticos. Además de la defensa tópica de los derechos individuales y de los equilibrios de poder de un orden constitucional liberal, en ellos se advierte también una fuerte reivindicación de la autoridad común de los ciudadanos, junto a una valorización ética de una ciudadanía inducida a ejercer activamente, no sin ciertas reminiscencias clásicas, las libertades políticas, llamada a hacerse cargo de sus deberes cívicos y de sus responsabilidades de autogobierno, más que a disfrutar de una protección segura de sus autonomías individuales o de su bienestar privado ${ }^{4}$.

Por cierto, las fundaciones teóricas de Aréchaga, dirigidas contra una recíproca relativización instrumental de las autonomías individuales y de las libertades positivas de los ciudadanos, vendrán precedidas de solemnes alusiones al primado metafísico de los derechos naturales, a su vez explicados por esencias deístas. Pero estos trasfondos filosóficos no impedirán que Aréchaga dispense un tratamiento normativo a las libertades democráticas, ni que procure conceptualizar y valorizar sus rasgos específicos, en particular, los derechos y deberes inherentes a su pleno ejercicio. De ahí su particular interés por reconstruir las conexiones prácticas o normativas entre la libertad política y las obligaciones del ciudadano y su enfática valorización de la naturaleza cívico-moral del sufragio, acompañada de una decidida reivindicación del voto público y obligatorio.

Del lado republicano del pensamiento de Aréchaga, las libertades políticas no son vistas como un instrumento al servicio de la autonomía de los ciudadanos individualmente considerados o de sus preferencias personales. Antes bien, la participación en la vida política significa tomar parte en un poder de decisión colectiva $\mathrm{y}$ en una autoridad común que, como tal, exige igualdad de trato y el ejercicio de responsabilidades participativas restrictivas de las autonomías individuales, no tanto en nombre de un reforzamiento moral de dichas autonomías, caro al pensamiento liberal (Nino, 2013), sino en virtud de un perfeccionismo cívico y del fortalecimiento del poder colectivo de los ciudadanos. La consideración privilegiada de la naturaleza política y activa de la ciudadanía excluye así su teorización en términos atomistas o privatistas, descartándose también su asimilación a un derecho facultativo de individuos independientes, celosos de su autonomía personal. En definitiva, la libertad política, en el sentido republicano que le atribuyera Aréchaga, con vistas a

4 Sostuvo Aréchaga: "No hay, sin duda alguna poder sobre la tierra que tenga el derecho de encadenar la libertad individual o de privar a la sociedad de su soberanía, aunque aquélla sea inepta para gobernarse a si misma y ésta perjudique los intereses privados porque estos son verdaderos principios absolutos, elementos esencialísimos y bases fundamentales de la organización social y politica de los pueblos impuestos por el supremo ordenador de las humanas sociedades" (Jiménez de Aréchaga, 1884, p. 293). 
legitimar su ejercicio democrático, significa, entre otras cosas, la libertad positiva de los miembros de la sociedad de decidir en conjunto, en diversas investiduras públicas o representativas, lo que estimen justo y conveniente para todos 5 .

Por otro lado, en Aréchaga se contemplan los fundamentos normativos de una representación política plural, igualmente concebida para responder a las opiniones públicas de los representados y para guiarse por una autónoma razón deliberativa, tendiente a contrastar y a favorecer intersubjetivamente los principios e intereses públicos más legítimos o relevantes. Así, junto a la asunción del principio -constitucionalmente regulado- de soberanía popular y a la exigencia categórica de un trato justo a todas las opiniones públicas, Aréchaga abordó en forma conjunta los problemas relacionados con los intereses disímiles del binomio principal-agente y con la deseabilidad de una representación autónoma y deliberativa, acaso más propia de una política de la virtud que de una racionalidad calculadora o maximizadora de intereses electorales ${ }^{6}$.

\subsection{Democracia, ciudadanía y activismo político}

La defensa normativa que realizara Aréchaga de una ciudadanía ampliada remite, básicamente, a una equivalencia política, en su época cuestionada, como tal, desde tiendas conservadoras ${ }^{7}$. Siendo la ciudadanía -y el sufragio- un derecho conferido a sí mismos por los miembros de la sociedad en el ejercicio pleno de su autoridad común, los factores excluyentes de dicha condición debían minimizarse, según este autor, descartándose las discriminaciones de clase, educacionales o relacionadas con la nacionalidad (Jiménez de Aréchaga, 1884, p. 50) ${ }^{8}$.

En sintonía con algunos círculos nativos del pensamiento teórico-práctico, Aréchaga puso en cuestión, en primer lugar, los impedimentos económicos de la ciudadanía, desestimando la idea de una relación causal o virtuosa entre propiedad y civismo, sosteniendo que las aptitudes para la vida política no cabía asociarlas, ni de hecho ni de derecho, al patrimonio (p. 62). En segundo lugar, Aréchaga combatió

5 La nómina convencional de pensadores republicanos incluye a Aristóteles, Cicerón, Maquiavelo, Harrington, Rousseau y los federalistas norteamericanos. Entre la enorme cantidad de trabajos sobre el republicanismo que podrían citarse cabe mencionar a Tercheck (1997), Pettit (1997), Audier (2004), Brugger (1999), Haakonsen (1995) y Gargarella, Martí y Ovejero (2004). Para una recopilación de estudios sobre el republicanismo latinoamericano véase Aguilar y Rojas (2002) y para el caso uruguayo Caetano (2011) y Gallardo (2006).

6 Para una aproximación al enfoque principal-agente véase el frecuentado libro de Przeworski, Stokes y Manin (1999), y para distintas versiones de la teoría deliberativa de la política puede consultarse Bohman (1997), Elster (1998) y Gallardo (2009).

7 Desde la Revista de El Ateneo, durante la década de 1880, el joven Martín C. Martínez, representante de un novel pensamiento positivista en el Uruguay, mezclado con algunas dosis de realismo político y con valores políticos conservadores, dirigirá los más severos cuestionamientos al universalismo racionalista de Aréchaga y a su reivindicación categórica de la igualdad ciudadana y del sufragio universal (Martínez, 1884, 1885a y 1885b).

8 La Constitución de 1917 suprimió los impedimentos patrimoniales y educativos del sufragio establecidos por la Carta de 1830, adoptando el sufragio universal masculino, librando al voto de las Cámaras Legislativas los derechos políticos de la mujer, incorporados a la Constitución de 1934. 
la exclusión política de los analfabetos, por injusta o por importar un falseamiento del sistema representativo, poniendo a su vez en entredicho la idea de una virtuosa relación de causa-efecto entre la instrucción y el ejercicio responsable del voto. En compañía de gran parte de sus congéneres doctorales, contrarios al ideal político educacionista, defendido en el medio local, entre muchos otros, por José Pedro Varela, Aréchaga desestimó la doctrina del sustento educacional del ciudadano, denunciando el "apasionamiento noble pero exagerado de los modernos educacionistas, que abrigan la infantil ilusión de que sólo en las escuelas se pueden formar los ciudadanos" (p. 53). Para Aréchaga el lugar central que la teoría política educacionista le asignara a la escuela pública debía ocuparlo el Municipio, al que consideró como la "verdadera escuela primaria de la ciudadanía”, inspirándose en un pensamiento político municipalista, de claras reminiscencias tocquevilianas ${ }^{9}$. Y, en tercer lugar, Aréchaga privilegió el criterio de residencia frente al de nacionalidad como fundamento de los derechos políticos, con vistas a defender la ciudadanía imperativa u obligatoria de los extranjeros, postura que tradujo en una fallida iniciativa legislativa, alineada con otras del mismo tenor, también fracasadas. Si bien la idea de una rápida incorporación de los inmigrantes a la vida política nacional dejará entrever, en Aréchaga y en sus demás defensores históricos, cierto desdén letrado hacia las tradiciones de la política criolla, junto a una ilustrada creencia en los valores civilizatorios de los extranjeros, de todos modos vendrá fundada en la convicción de una obligación moral hacia los residentes no-nacionales, cuya condición de miembros plenos de la sociedad, su igualdad civil y su aporte al bienestar general debían reforzarse mediante una igualación política y una normatividad imperativa de sus derechos políticos ${ }^{10}$.

Por otra parte, dada la adhesión de Aréchaga a las bondades sustanciales -más que técnicas o históricas- de la política representativa, su interés por la legitimación normativa del régimen democrático vendrá focalizada en el ciudadano elector y en la cuestión del voto, tópico sin duda crucial para las generaciones políticas uruguayas abocadas a transformar una convulsionada república de notables y caudillos tradicionales en una moderna democracia de sufragio popular y de partidos. En este sentido, junto a los cuestionamientos categóricos a las referidas restricciones ciudadanas,

9 En un párrafo de La libertad política consagrado al tema de la educación política puede leerse: "La instrucción elemental primaria ninguna relación tiene con el ejercicio de los derechos políticos. No es entonces justo ni racional exigir, para la adquisición del derecho de sufragio, una condición que, no sólo no es indispensable, sino que ni siquiera tiene relación directa con el conveniente ejercicio de esa función de soberanía. Es la instrucción politica la que se requiere para que un ciudadano pueda concurrir con su voto, de una manera regular y benéfica, a la elección periódica del personal de los poderes públicos; y ella sólo puede adquirirse mediante el ejercicio práctico de todas las funciones de soberania que corresponden a los ciudadanos en los pueblos libres. No es en la escuela, primaria o superior, en donde se forman los ciudadanos; tan grande y fecunda tarea pertenece a otras instituciones sociales" (Jiménez de Aréchaga, 1884, p. 55).

10 Dirá Aréchaga: "No es la nacionalidad la fuente de los derechos políticos; no es ella la que acuerda a un individuo el derecho de intervenir en las funciones de soberanía, sino el hecho de ser miembro de la sociedad, de poseer derechos civiles y tener participación en los intereses sociales cuya garantía y administración al Estado se confian... El extranjero que se domicilia en nuestro país, incorporándose por ese hecho a nuestra sociedad, siendo afectados sus derechos civiles por la acción de los poderes públicos de la misma manera que los nacionales, y adquiriendo, como miembro de la comunidad, participación en los intereses colectivos, debe concurrir a la formación de los gobiernos que van a tutelar y administrar esos derechos e intereses" (p. 72). 
Aréchaga reivindicó, en un clásico lenguaje demo-republicano, el voto público, por entonces vigente en el país y objeto de severos rechazos en nombre de la libertad del elector y de la igualdad política de los partidos. Incluso aconsejó la formación de un nuevo registro cívico en cada período electoral como forma de incentivar en los ciudadanos el cumplimiento habitual de sus obligaciones políticas (p. 307). Téngase en cuenta que la publicidad del voto, efectivizada en el momento de realizarse el escrutinio electoral, debía contribuir, según una doctrina de época, al ejercicio responsable del sufragio y al fortalecimiento del carácter cívico de los ciudadanos. Aréchaga adhirió a ambas teorías, desestimando los argumentos consustanciados con la independencia del elector, sosteniendo que la efectivización del voto público debía examinarse a la luz de las condiciones concretas de cada sociedad, destacando las circunstancias históricas que en el Uruguay favorecían dicha modalidad de sufragio ${ }^{11}$.

Adviértase también que en tiempos de Aréchaga la discusión sobre la naturaleza del voto giraba en torno a dos extremos teóricos: mientras algunos lo consideraban como un "derecho", otros lo asimilaban a una "función" asignada a los miembros del cuerpo político. Aréchaga desestimó el primer término de esta dualidad por entender que el voto no podía inscribirse en la jurisdicción de los derechos individuales, más adecuados, a su juicio, a la regulación de la libertad personal que al ejercicio de las libertades políticas. Pero también cuestionó la asimilación del sufragio a una "función pública", descartando su homologación a un "cargo" ejercido al servicio de la comunidad, rechazando su distribución conforme a una diferenciación de rangos de conciencia pública entre los individuos, entonces defendida por John Stuart Mil ${ }^{12}$.

De acuerdo a las distinciones conceptuales trazadas por Aréchaga, el voto no podría equipararse ni a un derecho de uso facultativo, adscripto a un círculo "negativo" o no interferido de libertades individuales, cuyo uso quedaría librado a los dictados de la conciencia individual o a una obligación puramente moral, ni a una función pública exigida de altos atributos cívicos o extra-políticos. Antes bien, el sufragio será visto por este autor como una investidura a la que los individuos acceden bajo el imperio de condiciones normativas de libertad e igualdad, de suyo sujeta al ejercicio responsable de una íntegra razón pública ${ }^{13}$.

11 Sostuvo Aréchaga: "Entre nosotros el único obstáculo que se opone a la publicidad del sufragio consiste en los actos de violencia, en las luchas brutales que se producen siempre en los momentos en que se verifican las elecciones, que alejan de las urnas a los ciudadanos pacificos y a los elementos conservadores de la sociedad y las abandonan a los caprichos de los demagogos y de las turbas desmoralizadas. Luego, pues, haciendo secreto el voto en el momento de depositarse las balotas en las urnas, e impidiendo de esta manera que los electores conozcan el estado de la votación en el momento en que ella tiene lugar, se salvan los peligros que acabo de indicar. $Y$ dando publicidad al escrutinio, a la vez que no se tropieza con ningún inconveniente, que no corre peligro alguno la independencia de los electores, se consiguen todos los buenos efectos que produce el voto público" (1884, pp. 299-300).

12 La primera edición de la obra de Mill, Consideraciones sobre el gobierno representativo, es de 1861. En el Uruguay circuló casi inmediatamente una edición francesa, sin fecha de impresión, traducida por Dupont-White.

13 Sostuvo Aréchaga: "Mientras que el hombre ejerciendo sus derechos individuales, sólo dirige el desenvolvimiento de su personalidad, sólo afecta de una manera directa sus propios intereses, cuando concurre por medio del sufragio a la formación de los poderes públicos, su acción tiene por exclusivo objeto la dirección de los 
En consecuencia, Aréchaga sostuvo, al igual que otras voces de la ilustración política local y que los representantes de la Convención Constituyente de Buenos Aires de 1870-73, que el voto debía considerarse más como un "deber" que como un "derecho". Y en buena lógica republicana, defendió la participación obligatoria de los ciudadanos en las decisiones colectivas, poniendo énfasis en la especificidad y autonomía de las actuaciones ciudadanas, jerarquizando su fuerza vinculante y su impacto en el interés y destino de todos, por encima de su afectación a los intereses particulares de los individuos, sin dejar de advertir sobre los efectos negativos del abstencionismo político en la soledad política de los gobernantes o en el debilitamiento de la autoridad común de los ciudadanos ${ }^{14}$.

Además de destacar la experiencia de países en los que regía la obligatoriedad del voto, Aréchaga dirigió su batería de argumentos conceptuales y normativos contra quienes descreían en la capacidad de juicio político del ciudadano común. En tal sentido, acudió a una presunción teórica de autonomía individual y a la hipótesis de un efecto educativo de la participación democrática, una y otra replicadas en diversos ramales de la teoría normativa de la democracia. Así, por un lado, evocó el buen uso de las obligaciones electorales por parte del ciudadano profano, aún por el más indiferente, quien obligado a elegir nunca votaría, según dijo, para perjudicar su propio interés. Y por otro lado, especuló sobre los impactos educativos de la participación política o sobre sus consecuencias favorables para la ilustración de los intereses bien entendidos de los ciudadanos ${ }^{15}$. Puestas las cosas así, la capacidad de las instituciones

intereses sociales [...] la expresión ciudadano designa al hombre, no bajo el aspecto de ser individual y autónomo, sino como elemento componente de la sociedad y como miembro, en consecuencia, de la soberanía nacional [...] nnoo iudadanizaci, l rudencial, de las experiencias de distintos regres,constitutivas iudadanizaciAsi como los derechos individuales, por consistir en las diversas direcciones que puede tomar la actividad del hombre, desenvolviéndose libremente para realizar los fines especiales de la vida individual, por constituir los atributos de la personalidad humana, por importar un poder del hombre sobre si mismo, son ejercidos por los individuos teniendo sólo en cuenta su interés personal, sus deseos y aún sus caprichos, sin más restricción que el respeto de la voluntad ajena, los derechos politicos, por ser funciones propias del organismo social, por poseerlos los ciudadanos unicamente a titulo de elementos componentes de ese organismo, y por tener por exclusivo objeto la dirección de los intereses públicos, sólo deben ser ejercidos teniéndose en consideración el bien público, los intereses politicos de la sociedad" (Jiménez de Aréchaga, 1884, pp. 6, 16-17).

14 "Es, a la verdad, enteramente impropia la expresión derechos politicos, empleada por los legisladores y tratadistas para designar las diversas funciones de soberania ejercidas por la sociedad [...] y es un error, como lo ha dicho Florentino González, confundir en una misma denominación las facultades del hombre que puede poner en ejercicio individualmente y para su provecho particular, como son las que conocemos con el nombre de derechos individuales, con las funciones que ejerce como miembro de la sociedad para proporcionar a esta los medios de emplear el poder soberano para reglar y administrar sus intereses colectivos de la manera más convincente [...] Entiendo pues, que siendo jurídicamente obligatorio para los ciudadanos el ejercicio del sufragio $y$ de toda otra función de soberanía, sería más propio llamar a estas deberes políticos reservando la palabra derecho para designar las libertades individuales" (pp. 27-29).

15 En consonancia con la teoría de las cualidades indirectas -más que epistémicas y sustantivas- de los procesos democráticos, Aréchaga sostuvo: "Obligados a mezclarse en el movimiento político de la sociedad, los ciudadanos adquirirán necesariamente esa instrucción politica que enseña cuan estrechamente unidos están los intereses públicos con el interés individual y cuán esencial es para el orden y para la prosperidad social el más amplio ejercicio de la libertad política. De modo, pues, que el ejercicio obligado del sufragio por parte de los que al presente se abstienen de votar produciría el efecto de sacarlos de su actual indiferencia de los intereses públicos 
políticas para involucrar a sujetos reconocidos en su autónoma condición individual y para formar su espíritu público, adquiere, al modo de Tocqueville y Stuart Mill, el rango de un atributo diferencial y decisivo del régimen democrático, de controvertida pertinencia ontológica o empírica, puesta de manifiesto en múltiples debates de la teoría política contemporánea. Y como sustento argumental de esta valoración, Aréchaga echó mano a dos fundamentos teóricos que suelen repartirse las teorías democráticas, conforme a la adopción de posiciones extremas o de síntesis respecto al dualismo de las libertades antiguas y modernas, negativas o no-interferidas y positivas o de auto-gobierno (Berlin, 1988). De acuerdo a uno de ellos, la democracia se funda en un principio anti-paternalista de autonomía individual y en la autoridad de los individuos para juzgar sus mejores intereses, con independencia de su envolvimiento en los procesos políticos; mientras que según el otro argumento, la democracia depende del espíritu cívico de los ciudadanos y de su involucramiento en la formación endógena de los juicios públicos en sedes políticas, confiándose su calidad normativa y sustantiva a los procedimientos participativos de auto-determinación colectiva (Nino, 2013; Dworkin, 2008; Habermas y Rawls, 1998).

En todo caso, más allá de las controvertibles razones de Aréchaga en favor de la publicidad y obligatoriedad del voto, lo cierto es que se trata de un pensamiento y un discurso compenetrados con los bienes intrínsecos de la política, trascendentes de las exigencias normativas de una democracia liberal, llamados a desbordar, incluso, las reglas de juego de un procedimiento democrático consagrado a asegurar un trato neutral a las preferencias no interferidas de los ciudadanos o de quienes se interesen voluntariamente por las cosas políticas. La idea de democracia que transmite Aréchaga se recorta así sobre un telón de fondo de principios y valores demo-republicanos, dirigidos contra la instrumentalización y soledad de la política. Conforme a esta lógica teórica, el concepto del voto como un deber de los ciudadanos en tanto miembros de un cuerpo político encargado de cumplir funciones de autogobierno, al igual que la reivindicación del voto público como un mecanismo regulador del ejercicio responsable de las libertades y decisiones políticas desbordan el fuero autónomo de las preferencias individuales, yendo a contrapelo de una variante de comunidad liberal, fundada en el valor central de la independencia o autonomía de los individuos, inscribiéndose, en suma, en la tradición cívica y pro-política de las repúblicas antiguas y modernas.

\section{Representación política: entre el interés racional del político y la virtud de un selecto cuerpo deliberativo}

En el pensamiento de Aréchaga se advierte la influencia de la tradición institucionalista de los teóricos federalistas norteamericanos, ampliamente citados en sus escritos. Influencia por demás palpable en algunos de los fundamentos estructurales del ordenamiento constitucional uruguayo. Así, la valorización simultánea que realizara

y de hacerlos comprender las ventajas que aún desde el punto de vista de sus intereses personales reportarian tomando una parte activa en la politica, ejerciendo la función electoral" (pp. 35-36). 
Aréchaga del principio de ciudadanía universal masculina, de una estructura institucional multiplicadora de las opiniones públicas y de una selecta representación política, sustitutiva de las asambleas directas, distinguida por sus atributos morales y deliberativos más que por su representatividad local o sociológica, sintoniza con las invenciones originarias de la república norteamericana. Incluso, sus afinidades con la matriz fundacional de los Estados Unidos se verifican en sus explícitas adhesiones al régimen presidencialista y a la vieja tradición municipalista de Nueva Inglaterra.

Aún cuando estas ideas pertenecen a la escuela del constitucionalismo liberal-republicano del siglo XVIII, en parte compenetrada con un afán de moderación de los arrestos coercitivos del poder político (Arendt, 1965), en el horizonte de Aréchaga se dibujan también otros intereses normativos e institucionales, relacionados con algunos temas y problemas centrales de la democracia en general, y de la democracia de partidos en particular. En este otro terreno teórico y práctico, despunta un lenguaje más consustanciado con la racionalidad de agentes calculadores o maximizadores de intereses políticos que con la excelencia política o la razonabilidad común de un refinado civismo patricio o elitista. Se trata, además, de un mundo conceptual permeado por diversas influencias teóricas y por distintas cuestiones prácticas, entre ellas, las inherentes al presidencialismo de progenie norteamericana y las propias del régimen de representación proporcional, vehiculadas por la tradición parlamentaria de la Europa continental ${ }^{16}$.

Como quiera que sea, Aréchaga procuró sentar los principios fundantes de una representación política plural y del régimen electoral de representación propor-

16 Por cierto, que este compendio de temas e intereses políticos, corrientemente amalgamados en las primeras camadas de la ilustración política local, no tiene necesariamente que leerse como una muestra más de un manido exotismo constitucional o sincretismo teórico latinoamericano. Más allá de los compromisos normativos y axiológicos que habitan la teoría política democrática (Dahl, 1991), en el discurso de Aréchaga se refleja la variedad de conceptos y principios que animaran el pensamiento fundacional de las democracias originarias o de la "primera ola" democratizadora (Huntington, 1994). Se trata de un ideario político informado por un diálogo fluido entre la filosofía moral, el derecho, la historia y la ciencia política, tendiente a conjugar la moralidad política de una modernidad liberal-republicana con el realismo de las prácticas inclusivas y disputativas de la democracia. Dichas mixturas se advierten en los prospectos teóricos originarios de las democracias contemporáneas, en la similar atención que estos les acordaran a las condiciones de moderación del poder político o, si se quiere, a la política de la voluntad, y a los fundamentos prácticos de una autoridad democrática duradera, y de ahí, quizás, su longevidad. Tales preocupaciones no hacen sino revelar, dicho sea de paso, la distancia que separa los linajes conceptuales y normativos de las democracias de primera generación de los lenguajes que hoy definen la democracia, en gran parte al calor de la teoría de la elección racional o de la escuela de la "transitología" democrática, como un juego contingente entre ganadores y perdedores provisorios y reversibles, motivados a interactuar por intereses estratégicos y a medir sus logros políticos por estados de cosas optimizados desde la perspectiva subjetiva de agentes librados al uso racional de sus recursos de poder (Huntington, 1994; Przeworski, 2010; Schmitter y Karl, 1993). Pese a que el pensamiento de los regímenes democráticos embrionarios contiene múltiples referencias a la naturaleza adversativa de la democracia, sin que falten diversas aprehensiones hacia la "tiranía de las mayorías" o a la "política de facción", resultan sin duda poco conmensurables con el agnosticismo normativo de los actuales paradigmas democráticos, más próximos a una racionalización de lo dado que a las promesas aún "incumplidas" de la democracia, más adecuados acaso al desempeńo exitoso de las artes especializadas de la política profesional que al fortalecimiento práctico o institucional del poder común de los ciudadanos y sus agentes. 
cional, al que quiso imprimirle, al igual que John Stuart Mill, una fuerte lógica de vertebración política y programática, en desmedro de una mecánica agregativa de preferencias exógenas al proceso político, procurando jerarquizar una jurisdicción política nacional, susceptible de proporcionarle a las empresas partidarias amplias plataformas gubernativas y extendidas adhesiones ciudadanas. Más allá de sus referencias al contexto histórico inmediato, Aréchaga abundó en estos asuntos con un fuerte celo normativo, buscando erradicar de la vida democrática los agregacionismos atomistas, las representaciones fragmentadas y los faccionalismos mayoritarios, sobre la base de una democracia pluralmente configurada en las asambleas representativas y en los partidos.

En El Poder Legislativo, texto escrito en 1887, se evidencian distintos empeños por articular una teoría justificativa de la validez y viabilidad del régimen representativo, en momentos en que este atravesaba por serias dificultades dentro y fuera de fronteras. Al unísono con la revisión por parte del constitucionalismo liberal-republicano de la idea de una expresión directa de la voluntad popular, Aréchaga descartó el mandato imperativo de los representantes, alejándose también de las teorías políticas que, ya en el horizonte y en los comienzos del siglo XX, irán reconciliándose con la realidad de un poder omnímodo o auto-reproducido de los elegidos (Weber, 1971; Michels, 1983).

Tres aspectos retuvieron la atención conceptual y normativa de Aréchaga: i) las fuentes constitutivas de la representación política; ii) los mecanismos garantes de la responsividad de los elegidos ante sus electores y iii) las condiciones de un desempeño autónomo y deliberativo de los representantes frente a la opinión popular y al recuento periódico de las preferencias individuales de los votantes. En el tratamiento de estos temas, Aréchaga acordó una especial atención a las reglas de elección de los representantes, materia que abordó con los fríos tecnicismos de un especialista y con el ardor de un ferviente defensor de la causa del régimen electoral de representación proporcional ${ }^{17}$.

Respecto a las fuentes constitutivas del régimen representativo, Aréchaga se hizo eco de un ideario liberal-republicano que, en lugar de avenirse a una representatividad "descriptiva" o derivada de un entramado pre-político, socio-económico o corporativo, reivindicó una representación ciudadana uniforme y escindida del mundo social. Aún reconociendo que la representación política debía reflejar una "imagen reducida pero perfecta de la nación" para que las leyes sintonicen con "las verdaderas necesidades del país y con las ideas, las tendencias y las preocupaciones sociales" descartó una correspondencia lineal o sociológica entre representantes y representados, asimilando la legitimidad de la representación política a los principios normativos de una elección ciudadana, centrada en opiniones públicas articuladas

17 La regla de la representación proporcional contó con crecientes apoyos en la Europa continental de la segunda mitad del siglo XIX. En la región, sus primeros afianzamientos legales remontan a la Convención Constitucional de Buenos Aires de 1870-73. Y en Uruguay, dicho régimen recogió la adhesión de los círculos políticos letrados del último tercio del siglo XIX, siendo incorporado al derecho electoral y a la Constitución Nacional desde 1917. Ya en 1876, Aréchaga redactó un proyecto de ley favorable al régimen de representación proporcional que fuera rechazado por el gobierno de facto del Coronel Lorenzo Latorre. 
y administradas por partidos políticos (Jiménez de Aréchaga, 1887, pp. 88, 140) ${ }^{18}$. En cuanto al doble imperativo de responsabilidad e independencia de los representantes ante los representados, Aréchaga procuró aunar ambos requerimientos, inspirándose en distintos modelos políticos, transitando por dos tipos ideales de democracia representativa, según ponga mayor o menor énfasis en uno u otro término del binomio delegación-autonomía, conforme reconozca, si se quiere, distintas dosis de interés propio y de virtud cívica entre los representantes políticos. Así, por un lado, Aréchaga se hizo cargo de los riesgos del poder discrecional de los representantes políticos, tal como lo revelan sus avales teóricos a diversos arreglos institucionales tendientes a garantizar una frecuente rendición de cuentas de los elegidos ante sus electores. Desde esta perspectiva, la calidad democrática de la representación política, esto es, su capacidad de respuesta ante las demandas de los representados, excede la confianza en sus atributos cívico-morales, dependiendo, más bien, de una sujeción mecánica de los intereses de los elegidos a los de sus votantes, librada al artificio prudencial de una renovación periódica de sus mandatos políticos. En otras palabras, conforme a la teoría del binomio principal-agente, el interés racional del representante por mantener sus bases de adhesión traería aparejada una conducta racionalmente responsiva ante los deseos de los representados, quienes dispondrían del recurso de reelegirlos o no. La democracia representativa ofrecería así un monitoreo externo a la conciencia moral de los legisladores o de su nivel promedialmente escaso de motivaciones virtuosas ${ }^{19}$.

Sin embargo, Aréchaga se hará eco también de otras exigencias normativas, mayormente consustanciadas con la validez sustantiva de los procesos democráticos, de alguna manera inconmensurables con el poder discrecional o con el accionar estratégico de los representantes políticos, más pendientes, en todo caso, de sus dotaciones cívico-morales y de sus interacciones deliberativas que de la articulación mecánica de una racionalidad calculadora con los escrutinios periódicos de las preferencias electorales. De ahí que para Aréchaga, como para John Madison, uno de los "padres fundadores" de la república norteamericana, las democracias modernas estaban llamadas a contar con asambleas "moralmente responsables por sus actos ante la opinión pública", integradas por "los elementos superiores de la sociedad", debiendo confiarse, incluso, como diría Jefferson, a una aristocracia electiva o "natural". En este otro encuadre teórico, la legitimidad de las asambleas representativas no depende tan sólo de su fidelidad a las preferencias de los votantes sino de su independencia cívica y de los procesos de formación autónoma de una "voluntad pública", en parte

18 Sostuvo Aréchaga: "En un país democrático no existe más que un solo elemento susceptible de ser representado por los poderes públicos: la masa general de los ciudadanos, la sociedad politica en su unidad orgánica, con todos sus derechos y todos sus intereses" (Jiménez de Aréchaga, 1887, p. 168). Adviértase que esta última proposición refleja una idea moderna, aunque orgánica de la sociedad, literalmente discordante con la tradición individualista del contractualismo liberal (pp. 137-138).

19 "La frecuente renovación de sus miembros [de la Cámara de Diputados] permite que en su seno se operen siempre las mismas modificaciones que sufran las ideas y las necesidades del pueblo [...] siendo muy frecuente la renovación del personal de la Cámara de Representantes, están estos vivamente interesados en conservar su popularidad presente, ya para conseguir una reelección, ya para poder gozar de cualquiera otra de las ventajas que ella ofrece en el movimiento politico de las sociedades" (pp. 106, 197). 
sujeta, según el credo filosófico de Aréchaga, al derecho natural o constitucional, y en parte guiada también por una racionalidad deliberativa, centrada en principios de justicia o de interés público, confiada al pequeño número y desprovista de las retóricas efectistas del "político sagaz" (pp. 91, 142).

Aréchaga desestimó, inclusive, las elecciones demasiado frecuentes por entender que incitaban a los partidos políticos a mantenerse en un "estado de viva lucha". Si bien la duración de los mandatos debía ajustarse, a su juicio, a la necesidad de "mantener vivo en el espiritu de los representantes el sentimiento de su dependencia y de su responsabilidad moral ante la opinión pública" también sostuvo que su extensión debía asegurar una actuación independiente, evitando "una sumisión servil a todos los caprichos populares". Desde esta perspectiva, la independencia de acción de los representantes vendría asegurada por la adquisición de "los conocimientos y la experiencia indispensables al buen desempeño de sus funciones" y por su disposición al sacrificio de una "popularidad presente a cambio de una sólida reputación futura" (pp. 108, 112).

Conforme a esta lógica de domesticación de la racionalidad calculadora de los representantes, Aréchaga defendió la elección en segundo grado de los miembros del Senado, mediante colegios electorales integrados por ciudadanos "de mayor ilustración e idoneidad" (p. 284). Téngase en cuenta que, bajo la influencia del republicanismo noratlántico, el mecanismo de elección indirecta gozaba de buena reputación entre los círculos políticos letrados del siglo XIX, quienes lo veían como un dispositivo adecuado para confiar la segunda cámara a ciudadanos con suficiente idoneidad política y moral como para compensar "los vicios inherentes a la constitución de la cámara popular", electa directamente por el pueblo, y más propicia, en la visión de Aréchaga y de los framers norteamericanos, a "la representación del sentimiento que dé la razón pública" (p. 125)

En cualquier caso, la idea de una representación bifronte, a la vez democrática y de altos estándares cívicos, da cuenta de un instrumental teórico demo-republicano, tendiente a equiparar en un mismo plano de valor y en una misma fórmula institucional, en términos acaso controvertibles o contradictorios, los componentes responsivos y deliberativos, cuantitativos y cualitativos de la democracia. Dicho de otra manera, del trasfondo de imperativos morales y prudenciales de Aréchaga se

20 La elección en segundo grado de los senadores, a mayoría absoluta y en colegios electorales sujetos a la representación proporcional, y no a una elección por mayoría simple, tal como fuera establecido por la primera constitución, debía servir, Según Aréchaga, para elegir ciudadanos respaldados en amplios consensos públicos, dotados de las competencias y las virtudes de verdaderos "hombres de Estado". Con arreglo a este criterio, el Senado debía funcionar como un foro deliberante en el que los representantes de "la masa general de los ciudadanos" y no de una sección o circunscripción electoral, debían promover el interés público y general, anteponiendo los dictados de la justicia a los cálculos estratégicos o de poder (p. 167). No hay que olvidar el ascendiente que ejerciera, entre los círculos letrados vernáculos, la descripción de Alexis de Tocqueville en La Democracia en América de los representantes y senadores norteamericanos, electos respectivamente en primer y segundo grado, en particular, la celebridad adquirida por los rasgos de "vulgaridad" con que Tocqueville retratara a los primeros y de "honorabilidad" que percibiera en los segundos. Aréchaga esperaba ver reproducidos estos distingos entre los diputados y senadores locales al someterlos a distintos procedimientos electivos, haciendo lugar, si cabe decirlo, a la política candombera entre los primeros y doctoral entre los segundos. 
desprende su doble adhesión al elitismo cívico y a un realismo democrático, a tono con algunos intereses teóricos relevantes o de larga duración. Así, en su tránsito por esta doble sensibilidad cívico-democrática, se contemplan dos cosas a la vez: por una parte, se rinde tributo a una exigencia categórica de idoneidad moral e independencia cívica de los elegidos, cuya "voluntad pública" es librada a una trascendente razón deliberativa, libre de cálculos estratégicos o electorales; y por otra, se da cuenta del problema del poder discrecional de los representantes, cuya solución teórica vendría a depender del imperativo hipotético de una convergencia, acaso contingente o empíricamente dificultosa, entre sus intereses y los de los representados. En el primer caso, Aréchaga se revelará poco sensible, como sus ancestros liberal-republicanos, al déficit democrático derivado de la jerarquización cívica de una selecta y moralmente saneada elite legislativa, uniformemente guiada por una única o común "razón pública"; y en el segundo, al igual que los actuales defensores de una democracia minimalista, se mostrará poco confiado en la economía moral de los cuerpos representativos, en la eficacia racional de su espíritu público o en sus dotaciones deliberativas (pp. 142, 192 y 287$)^{21}$.

Por otra parte, los escritos de Aréchaga contienen los fundamentos normativos de una representación política plural, sensible a los derechos de las minorías políticas y a la representatividad de diversas opiniones públicas, tal como lo evidencian sus defensas del régimen de representación proporcional y del doble voto simultáneo, dirigido a instaurar una doble lógica pluralista en las asambleas representativas y en los partidos políticos ${ }^{22}$. Sin duda, en las conexiones conceptuales y prácticas que estableciera Aréchaga entre la representación política y la justicia electoral, inspiradas en la escuela teórica de John Stuart Mill, se advierte una fuerte preocupación por ase-

21 Aréchaga dejó testimonio de esta tensa combinación de un principio de control de los intereses políticos de los representantes con el despliegue autónomo de las virtudes y excelencias de una selecta representación política (Manin, 1998). Además de la carga positiva que le asignó a su proposición de que el pueblo "delega el ejercicio de la función de soberanía, tomando las medidas necesarias para evitar que cometan abusos y atentados, esto es, determinando sus atribuciones y estableciendo los medios de impedir que salgan fuera de la órbita de acción que se les ha marcado", sostuvo que "el principio de representación, aplicado al gobierno de las sociedades, tiene precisamente por objeto la realización práctica de este pensamiento de Jefferson, atribuyendo, mediante la elección popular, las funciones del Poder Público a los hombres superiores que, por su ilustración, su experiencia y su moralidad, están en condiciones de hacer lo que, por su escasísima cultura, no puede llevar a cabo la multitud" (Jiménez de Aréchaga, 1887, p. 284).

22 Aréchaga fue un firme defensor del sistema de doble voto simultáneo, tomado del belga J. Borely y originariamente identificado como una de las fórmulas de "concurrencia de listas". Esta regla electoral, establecida en la provincia de Buenos Aires en 1876 y adoptada en el Uruguay en 1910, vino a consagrar el ejercicio de un doble voto dirigido al partido y a una de sus listas de candidatos, permitiendo que sumen sus sufragios, computándose los votos por partido y por el orden de las listas ganadoras dentro de cada uno de ellos, de modo de distribuir los cargos electivos en base a este doble conteo. Desde su adopción en el referido año, el doble voto simultáneo pasó a constituirse en una pieza central del engranaje representativo uruguayo, convirtiéndose en la piedra angular de su lógica de competencia electoral y de su cultura de compromiso a niveles intra e inter partidario durante casi todo el siglo XX. En la versión de Aréchaga, el doble voto simultáneo debía consagrar la libertad del elector para ordenar la composición de las listas o de los candidatos de acuerdo a sus preferencias, lo cual no fue tenido en cuenta por la normativa adoptada (pp. 217-219). 
gurar, más de jure que de facto, una domesticación pluralista del mando decisionista de los liderazgos políticos y del poder de las cúpulas partidarias, tal como se refleja en su rechazo a la regla de representación -que no de decisión-mayoritaria, en nombre del deber moral de dispensar un igual trato representativo a todas las opiniones, a todos los partidos y a todos los votos ${ }^{23}$.

Con todo, en su defensa de una configuración pluralista de la representación política y la competencia partidaria, en momentos en que algunas corrientes partidarias locales se veían excluidas de una representación parlamentaria por imperio del régimen electoral mayoritario, se hará sentir también, como ya anticipáramos, el deseo de inscribir las diversas corrientes de opinión pública en una razón discursiva o deliberativa, susceptible de procesar una autónoma o trascendente voluntad pública, tendiente a diferenciar normativamente las decisiones debidamente justificadas y legítimamente vinculantes de las conveniencias partidarias o de un fragmentado status quo pluralista.

Incluso, la importancia acordada por Aréchaga a la articulación discursiva de una voluntad cualitativa del cuerpo representativo, guiada por intereses públicos superiores y con efectos transformadores en las preferencias manifiestas de los ciudadanos, refleja el ascendiente de la escuela teórica de la "voluntad general", fundada en la primacía de lo general sobre lo particular, superior, en todo caso, a la voluntad derivada de compromisos entre representantes celosos de sus diferencias o racionalmente dispuestos a aceptar consensos compatibles con el reconocimiento de sus distintas identidades e intereses políticos ${ }^{24}$. Así, en el tono de un republicanismo afrancesado, poco amigable hacia los arraigos o intereses socialmente configurados, extraño a las políticas responsivas ante las demandas de cada circunscripción particular, Aréchaga prodigó elogios a una representación de carácter nacional, susceptible de inducir amplias miras políticas en los representantes, facultada para asegurar mayorías legítimas, consistentes y soberanas ${ }^{25}$.

23 Cabe recordar, aunque aquí no vamos a tratar el punto, que en los trabajos de este autor no sólo se recogen evidencias y datos contrastables de distintos regímenes de votación; también despunta una teoría de los sistemas electorales, relativamente independiente de las tradiciones y contingencias de cada contexto, a priori incondicionada por las imposiciones fácticas o estratégicas, cuyos criterios básicos de moralidad política tendrían un doble propósito fundacional y de evaluación crítica de las prácticas reales. 24 "Cada miembro de la Cámara de Representantes representa a la Nación entera, es un mandato de toda la sociedad, porque los habitantes de la circunscripción o departamento que lo han elegido han puesto en ejercicio para ello una facultad emanada de la soberanía, que es indivisible y reside en toda la sociedad por entero y no fraccionariamente en cada sección del pais [...] Es condición indispensable de la existencia de la sociedad que los intereses particulares se sometan a los intereses generales siempre que estos sean legitimos; $y$ por consiguiente, el diputado elegido por un departamento, cuyos intereses locales no sean favorecidos por un proyecto de ley que esté en armonía con los intereses generales del pais, debe darle su voto para dar asi satisfacción a esa primordial exigencia de la vida social" (pp. 72-73).

$25 \mathrm{Al}$ margen de su articulación de las bondades pluralistas de la representación proporcional, Aréchaga celebró que "el veredicto de la mayoría sea soberano", sosteniendo, en un léxico de ambiguas resonancias rousseaunianas, que: "la mayoría, para justificar su imperio, podría decir a la minoría estas palabras de Laboulaye: somos los más numerosos, probablemente los más ilustrados, sin duda alguna los más fuertes; la presunción es que tenemos razón; el interés de la sociedad, vuestro propio interés, exige que cedáis, porque de otra manera, el gobierno democrático no es posible" (Jiménez de Aréchaga, 1884, p. 114). Por lo demás, a 


\section{El legado normativo de Aréchaga}

Más allá de su afán por incorporar al mundo de las ideas y corrientes doctrinarias el conocimiento sistemático de los hechos políticos y de las realidades sociales, en el pensamiento de Aréchaga se advierten las marcas de una tradición teórica centrada en los imperativos de legitimación moral de las instituciones políticas, confiada en el poder político de la razón y en su capacidad para establecer los fundamentos de validez de una configuración deliberada y racional de las instituciones políticas. El pensamiento de Aréchaga encarna así una tradición de moralismo político en la que despuntan las clásicas demandas de un deber ser político, en parte atento a determinados contextos históricos y, en parte, contrapuesto normativamente a las realidades dadas o establecidas.

Con los instrumentos de un racionalismo principista, a tono con un ideal moderno de ordenamiento racional de las contingencias políticas, valiéndose de una tradición normativa de progenie liberal-republicana, históricamente tributaria de un elitismo cívico o de un democratismo moralizado, Aréchaga procuró salirle al paso a una serie de discriminaciones políticas y a la lenta evolución de las costumbres o transformaciones sociales. No obstante, la perspectiva de Aréchaga, aunque emparentada con los arquetipos filosóficos modeladores de los poderes políticos, refleja una vocación política e institucional, arraigada en la tradición docta nacional, tendiente a compatibilizar, para bien o para mal, las disciplinas teóricas de la moral y del derecho con una política públicamente aceptable y posible.

A su vez, el pensamiento de Aréchaga sintoniza con una tradición republicana de activismo ciudadano y perfeccionismo cívico no del todo compatible con el discurso moral de una comunidad liberal, neutral o agnóstica en cuestiones éticas y comprometida con el valor normativo de la autonomía personal. Aun cuando sus escritos se inscriben en un combate secular contra la "tendencia inherente de todo poder a ensanchar su esfera de acción" y contra las interferencias arbitrarias en la esfera de las libertades individuales, también se hacen eco de un conjunto de postulados filosóficos y políticos consustanciados con el potencial de autoridad común de los ciudadanos y con la integridad de las libertades políticas positivas, participativas y comunicativas, por no decir, con una autónoma y soberana formación discursiva de las voluntades democráticas.

Valiéndose del lenguaje de la filosofía práctica y del derecho constitucional, los textos de Aréchaga contienen algunas marcas originarias de la genética normativa de la democracia uruguaya, ya sea por su aliento a una temprana ampliación de la ciudadanía política, sujeta a una fuerte prescripción legal de los deberes cívicos, ya sea por su aporte teórico a los fundamentos morales e institucionales de un guión pluralista de la política de partidos en el Uruguay. En suma, por una razón o por otra, Aréchaga constituye un momento relevante de un programa de afirmación

la luz del principio de separación de poderes del régimen presidencial, Aréchaga defendió la regla de una renovación simultánea del Ejecutivo y del Legislativo con el fin de evitar fisuras entre ambos cuerpos y facilitar mayorías gubernativas, rechazando la realización de elecciones parciales durante cada mandato presidencial, previstas por la constitución de 1830 . 
normativa y práctica de una política nacional sustraída a la tiranía de las realidades establecidas o a la tutela de poderes incontestables.

Claro está, a la hora de hacer un balance crítico de las estructuras conceptuales de Aréchaga, así como de sus diversas posiciones filosóficas y políticas, descontadas las condicionantes y posibilidades históricas y semánticas de su discurso, no es posible ignorar las fallas o ambigüedades que actualmente se predican de todo pensamiento fundacional de la política y de las tradiciones ilustradas o humanistas que lo informan. Incluso, dejando de lado sus aporéticas mezclas de realismo democrático y perfeccionismo cívico, pasando por alto también su no tan singular solapamiento de lenguajes madisonianos y rousseaunianos, su pensamiento deja entrever, a la distancia, las limitaciones democráticas de un paradigma ciudadano uniforme y totalizante, escindido de arraigos sociales y de diferencias identitarias, en parte compensadas por un acercamiento pluralista a la política de partidos, aunque replicadas, a su vez, en sus afanes por extraer, de la pluralidad de opiniones ciudadanas discordantes, una "razón pública" o una voluntad común, trascendente de divisorias políticas o, en su defecto, confiada a una esclarecida y consistente mayoría soberana. Vistas a la distancia, sus ideas y sus prescripciones institucionales no parecen cuestionar el poder "natural" de un histórico elitismo político, ni tampoco se desmarcan de una visión regenerativa o teleológica de saneamiento moral de la democracia del número. Con todo, en una sobria traducción del discurso de Aréchaga a ciertas problemáticas teóricas actuales, se advierte su pretensión por erradicar un sistema de reglas de juego aséptico o neutral ante las preferencias privadas o agregadas de los individuos, aún hoy, precariamente justificado o evaluado por su producción de estados de cosas optimizadores de intereses establecidos o de equilibrios contingentes de poder.

Al cerrarse en el país el ciclo de una política de notables doctrinarios y de caudillos tradicionales y al abrirse paso, al calor de los arreglos constitucionales de 1917, una democracia de partidos, algunas recomendaciones prácticas de Aréchaga se harán palpables. La universalización del sufragio masculino, la emancipación del voto de determinadas restricciones extra-políticas, la representación proporcional y el doble voto simultáneo, irán alcanzando rango legal o constitucional. A su vez, el principio de representación pluralista que Aréchaga reivindicara como una bandera de principios contra el monismo político y la tutela electoral de las cúpulas partidarias se hará sentir en las dinámicas de competencia electoral de la política nacional, en sus dificultosas composiciones mayoritarias y en los regímenes de pactos y compromisos de una política "de partido y de fracción".

En cambio, otros mandatos normativos y usos semánticos, caros al pensamiento de Aréchaga, no correrán la misma suerte. Su empeño por resumir, en una misma fórmula práctica, los artificios institucionales de una democracia responsiva y una representación selecta y relativamente independiente de las preferencias de los votantes, así como su síntesis de un pluralismo partidista con una racionalidad deliberativa, sujeta al ejercicio ciudadano de la razón pública, ajena a cálculos estratégicos o electoralistas, no tuvieron mayores andamientos políticos en una democracia partido-céntrica, fuertemente dependiente de una distribución competitiva y negociada de los recursos de poder. Y en cuanto a la reivindicación normativa del 
voto público y obligatorio, desde nuestra perspectiva histórica es dable constatar que sus consecuencias prácticas fueron bastante dispares y atenuadas. El voto público fue desechado por los redactores de la Constitución de 1917, quienes prefirieron instaurar el voto secreto con vistas a asegurar la independencia y protección de las preferencias del elector, mientras que el sufragio obligatorio tuvo que esperar hasta el último tercio del siglo XX para convertirse en ley, cuando la mayoría de una agitada legislatura vislumbrara la conveniencia política, por no decir estratégica, de la obligatoriedad del voto, sometiéndola a los más exigentes controles públicos de la región, y no muchos recordaban las convicciones y razones demo-republicanas de Aréchaga en favor de una identidad cívico-moral entre los derechos políticos y el ejercicio responsable del autogobierno colectivo.

\section{Bibliografía}

Antonio, José y Aguilar, Rafael (2014). El republicanismo en Hispanoamérica. Ensayos de historia intelectual y política. Fondo de Cultura Económica.

Arendt, Hannah (1965). On Revolution. New York: Viking, 107.

Audier, Serge (2004). Les théories de la république. París: La Découverte.

Berlin, Isaiah (1988). Cuatro ensayos sobre la libertad. Madrid: Alianza Universidad.

Bohman, James (ed.) (1997). Deliberative Democracy, Essays on Reason and Politics. MIT Press.

Brugger, Bill (1999). Republican Theory in Political Thought: Virtuous or Virtual? New York: St. Martin's Press, Inc.

Buquet, D. y Castellano, E. (1995). “Representación Proporcional y Democracia en Uruguay”. Revista Uruguaya de Ciencia Política, $N^{\circ} 8$.

Caetano, Gerardo (2011). Ciudadanía, republicanismo y liberalismo en Uruguay (1910-1933). Montevideo: Ediciones de la Banda Oriental.

Caetano, G., Rilla, J. y Pérez, R. (1988). "La partidocracia uruguaya. Historia y teoría de la centralidad de los partidos”. Montevideo: Cuadernos del CLAEH, 44(4), 37-61.

Dahl, Robert (1991). La democracia y sus críticos. Buenos Aires: Paidós.

Dworkin, Ronald (2008). La democracia Posible: principios para un nuevo debate político. Barcelona; Paidós.

Elster, Jon (comp) (1998). La democracia deliberativa. Barcelona: Gedisa.

Gallardo, J. (2006). “Republicanismo, ciudadanía y política en el Uruguay”, en Isidoro Cheresky (comp.). Ciudadanía, sociedad civil y participación política. Buenos Aires: Miño y Dávila, pp. 443-478. (2009). "Elogio modesto a la deliberación política”. Revista Uruguaya de Ciencia Política, Vol. $18(1), 85-115$.

Haakonesen, K. (1995). "Republicanism", en Robert Goodin y Philip Pettit (eds.). A Companion to Contemporary Political Philosophy. Cambridge; Blackwell Publishers.

Habermas, Jurgen y Rawls, John (1998). Debate sobre el liberalismo político. Barcelona: Paidós.

Huntington, Samuel (1994). La Tercera Ola. La democratización a finales del siglo XX. Buenos Aires: Paidós.

Jiménez de Aréchaga, Justino (1884). La libertad Política. Montevideo: Librería Nacional. 
(1887). El poder legislativo. Montevideo: Barreiro y Ramos.

Lanzaro, Jorge (2012). "Continuidad y cambios en una vieja democracia de partidos. Uruguay 19102010". Montevideo: Cuadernos del CLAEH, 33(100), 37-77.

Manin, Bernard (1998). Los principios del gobierno representativo. Madrid: Alianza Editorial.

Martínez, Martín C. (1884): “Ideales positivistas”. Anales del Ateneo, Tomo VII, N 38, T. VII. (1885a). "El sufragio universal". Anales del Ateneo, Tomo VIII, No 43.

(1885b). "El voto proporcional a la capacidad". Anales del Ateneo, Tomo IX, No 52.

Michels, Robert (1983). Los Partidos Políticos. Un estudio sociológico de las tendencias oligárquicas de la democracia moderna. Buenos Aires: Editorial Amorrortu.

Nino, Carlos (2013). Una Teoría para la democracia. Buenos Aires: Siglo XXI Editores.

Gargarella, R., Martí, J. L., y Ovejero, F. (2004). Nuevas ideas republicanas: autogobierno y libertad. Barcelona: Paidós.

Pérez Antón, R. (1988). "Cuatro antagonismos sucesivos: la concreta instauración de la democracia uruguaya”. Revista Uruguaya de Ciencia Política, v. 2, pp. 41-60.

Pettit, Philip (1997). Republicanismo: una teoría sobre la libertad y el gobierno. Barcelona: Paidós.

Plant, Raymond (1991). Modern Political Thought. Cambridge: Basil Blackwell.

Przeworski, Adam (2010). Democracy and the limits of Self Government. Cambridge University Press.

Przeworski, A., Stokes, S. \& Manin, B. (eds.) (1999). Democracy, Accountability and Representation. New York: Cambridge University Press.

Sartori, Giovanni (1984). La Política. Lógica y método en las Ciencias Sociales. México: Fondo de Cultura Económica.

Shapiro, Ian (1990). Political Criticism. Berkeley: University of California Press.

Shmitter, P. y Karl, T. (1993). “¿Qué es y qué no es la Democracia?”. Sistema, No 116, septiembre.

Taylor, Charles (1990). Philosophy and the Human Sciences (Philosophical Papers, vol. 2). New York: Cambridge University Press.

Tercheck, Ronald (1997). Republican Paradoxes and Liberal Anxietes (Retrieving Neglected Fragments of Political Theory. New York: Rowman \& Littlefield Publishers, Inc.

Weale, Albert (1999): Democracy. London: Macmillan Press Ltd.

Weber, Max (1971). Escritos Políticos. Madrid: Alianza Editorial. (1980). El Político y el científico. Madrid: Alianza Editorial. 